\title{
Safety and pharmacokinetics of nintedanib and pirfenidone in idiopathic pulmonary fibrosis
}

\author{
Takashi Ogura1, Hiroyuki Taniguchi ${ }^{2}$, Arata Azuma ${ }^{3}$, Yoshikazu Inoue ${ }^{4}$, \\ Yasuhiro Kondoh ${ }^{2}$, Yoshinori Hasegawa ${ }^{5}$, Masashi Bando ${ }^{6}$, Shinji Abe ${ }^{3}$, \\ Yoshiro Mochizuki ${ }^{7}$, Kingo Chida ${ }^{8}$, Matthias Klüglich ${ }^{9}$, Tsuyoshi Fujimoto ${ }^{10}$, \\ Kotaro Okazaki ${ }^{10}$, Yusuke Tadayasu ${ }^{10}$, Wataru Sakamoto ${ }^{10}$ and \\ Yukihiko Sugiyama6
}

\begin{abstract}
Affiliations: 'Dept of Respiratory Medicine, Kanagawa Cardiovascular and Respiratory Center, Yokohama, Japan. ${ }^{2}$ Dept of Respiratory Medicine and Allergy, Tosei General Hospital, Aichi, Japan. ${ }^{3}$ Graduate School of Medicine Nippon Medical School, Tokyo, Japan. ${ }^{4}$ Dept of Diffuse Lung Diseases and Respiratory Failure, Clinical Research Center, National Hospital Organization Kinki-Chuo Chest Medical Center, Osaka, Japan. ${ }^{5}$ Dept of Respiratory Medicine, Nagoya University Graduate School of Medicine, Nagoya, Japan. ${ }^{6}$ Division of Pulmonary Medicine, Dept of Medicine, Jichi Medical University, Tochigi, Japan. ${ }^{7}$ Respiratory Medicine, Himeji Medical Center, Himeji, Japan. ${ }^{8}$ Second Division, Dept of Internal Medicine, Hamamatsu University School of Medicine, Hamamatsu, Japan. ${ }^{9}$ Boehringer Ingelheim Pharma GmbH \& Co. KG, Biberach, Germany. ${ }^{10}$ Nippon Boehringer Ingelheim Co. Ltd, Tokyo, Japan.
\end{abstract}

Correspondence: Hiroyuki Taniguchi, Dept of Respiratory Medicine and Allergy, Tosei General Hospital, 160 Nishioiwake-cho, Seto, Aichi, 489-8642, Japan. E-mail: hiro-tosei-lunglakkd.biglobe.ne.jp

ABSTRACT A randomised, double-blind, phase II, dose escalation trial was conducted to assess the safety, tolerability and pharmacokinetics of the tyrosine kinase inhibitor nintedanib, alone and when added to ongoing pirfenidone therapy, in Japanese patients with idiopathic pulmonary fibrosis.

50 Japanese patients were randomised to receive nintedanib or placebo in one of three cohorts (nintedanib $50 \mathrm{mg}$ twice daily or $100 \mathrm{mg}$ twice daily for 14 days, or $150 \mathrm{mg}$ twice daily for 28 days). Patients receiving pirfenidone at inclusion were stratified to every nintedanib dose group and placebo.

Adverse events were reported in nine out of 17 patients receiving nintedanib alone and 10 out of 21 patients receiving nintedanib added to pirfenidone. All adverse events were mild or moderate in intensity. Gastrointestinal disorders were the most common adverse event. Maximum plasma concentration and area under the curve at steady state for nintedanib and its metabolites tended to be lower when nintedanib was added to pirfenidone. Nintedanib had no effect on the pharmacokinetics of pirfenidone.

In conclusion, further study is needed to evaluate the safety and tolerability profile of nintedanib when added to pirfenidone in patients with idiopathic pulmonary fibrosis. There was a trend toward lower exposure of nintedanib when it was added to pirfenidone.

@ERSpublications

Nintedanib had acceptable safety and tolerability in Japanese patients with IPF http://ow.ly/DNG4k

For editorial comment see Eur Respir J 2015; 45: 1208-1210 [10.1183/09031936.00043915].

Received: Nov 132013 | Accepted after revision: Oct 222014 | First published online: Dec 112014

Clinical trial: This study is registered at www.clinicaltrials.gov with identifier number NCT01136174.

Support statement: This study was funded by Boehringer Ingelheim.

Conflicts of interest: Disclosures can be found alongside the online version of this article at erj.ersjournals.com

Copyright OERS 2015 


\section{Introduction}

Idiopathic pulmonary fibrosis (IPF) is a chronic, progressive interstitial lung disease characterised by fibrosis of the lung alveoli and interstitium $[1,2]$. Estimates of the worldwide prevalence of IPF range from two to 43 cases per 100000 people [2]. IPF has a poor prognosis [2] and there is a clinical need for novel therapies to improve outcomes in patients with IPF.

The pathogenesis of IPF is hypothesised to involve abnormal wound healing in response to epithelial injury [3]. The development of new treatments has focused on the signalling pathways involved in this response. Nintedanib (formerly known as BIBF 1120; Boehringer Ingelheim Pharma GmbH \& Co. KG, Ingelheim, Germany) is a potent intracellular inhibitor of tyrosine kinases that has been developed for the treatment of IPF and a number of cancer types. Nintedanib blocks the kinase activity of the platelet-derived growth factor, vascular endothelial growth factor and fibroblast growth factor receptors, all of which have been shown to be involved in the development of fibrosis $[4,5]$. The results of the phase II To Improve Pulmonary Fibrosis with BIBF-1120 (TOMORROW) trial suggested that nintedanib $150 \mathrm{mg}$ twice daily reduced decline in lung function in patients with IPF, with fewer acute exacerbations and preserved health-related quality of life [6]. Recently, the results of the two replicate phase III INPULSIS trials demonstrated that nintedanib reduced disease progression in patients with IPF by significantly reducing the rate of decline in forced vital capacity (FVC) [7]. In patients treated with nintedanib, the most common adverse events were gastrointestinal disorders, which accounted for the majority of discontinuations of study medication due to adverse eventss [7].

Pirfenidone (Shionogi \& Co. (Osaka, Japan) and InterMune Inc. (Brisbane, CA, USA)) was approved for the treatment of IPF in Japan in 2008 (Shionogi \& Co.) and for the treatment of adult patients with mild to moderate IPF in the European Union in 2011. In the phase III CAPACITY (Clinical Studies Assessing Pirfenidone in IPF: Research of Efficacy and Safety Outcomes) 2 trial, 72 weeks' treatment with pirfenidone $2403 \mathrm{mg} \cdot$ day $^{-1}$ significantly reduced the decline in percentage predicted FVC in patients with IPF versus placebo, but in the concurrent CAPACITY 1 trial, a significant difference from placebo was not observed [8]. Recently, the 52-week, phase III Assessment of Pirfenidone to Confirm Efficacy and Safety in Idiopathic Pulmonary Fibrosis (ASCEND) trial demonstrated a benefit of pirfenidone versus placebo on change from baseline in percentage predicted FVC [9]. In a phase III study in Japanese patients with IPF, 52 weeks' treatment with pirfenidone $180 \mathrm{mg} \cdot$ day $^{-1}$ significantly reduced the decline in vital capacity compared with placebo, with an adjusted mean change in vital capacity of $-0.09 \mathrm{~L}$ with pirfenidone $180 \mathrm{mg} \cdot \mathrm{day}^{-1}$ compared with $-0.16 \mathrm{~L}$ with placebo [10]. Photosensitivity was the most frequent adverse event in the phase III study in Japanese patients, experienced by $51.4 \%$ of patients on pirfenidone $180 \mathrm{mg} \cdot$ day $^{-1}$ versus $22.4 \%$ of patients on placebo [10]. However, in the international CAPACITY and ASCEND trials, the adverse event reported most frequently in patients treated with pirfenidone was nausea [8,9]. A recent review of adverse events reported in patients treated with pirfenidone based on a data set with a cumulative total exposure of 2059 person-exposure years reported that nausea and vomiting were reported by $40 \%$ and $18 \%$, respectively, of patients treated with pirfenidone [11].

There is some overlap in the adverse-event profiles of pirfenidone and nintedanib in patients with IPF in terms of gastrointestinal events and increases in liver enzymes [6-9]. However, pirfenidone and nintedanib have different metabolic profiles; pirfenidone is metabolised by various cytochrome P450 enzymes and predominantly excreted via the urine as the primary metabolite 5-carboxy-pirfenidone [12], whereas the metabolism of nintedanib is predominantly characterised by ester cleavage yielding BIBF $1202 \mathrm{ZW}$. BIBF $1202 \mathrm{ZW}$ is subsequently glucuronidated by various uridine diphosphate glucuronosyltransferases (UGTs) in the intestine and by UGT1A1 in the liver to form BIBF 1202 glucuronide. Both nintedanib metabolites are excreted via the biliary system into the faeces [13].

This phase II study was conducted to determine the safety, tolerability and pharmacokinetics of nintedanib and its metabolites, alone and when added to ongoing pirfenidone therapy, in Japanese patients with IPF. The pharmacokinetics of pirfenidone (alone and when nintedanib was co-administered) were also investigated.

\section{Materials and methods}

\section{Study subjects}

Patients eligible for inclusion were aged $\geqslant 40$ years, with IPF diagnosed according to the American Thoracic Society/European Respiratory Society consensus statement [1] and the fourth version of the diagnostic guidelines for idiopathic interstitial pneumonia in Japan [14] $<5$ years before screening, and high-resolution computed tomography within 12 months of randomisation that was consistent with a diagnosis of IPF. Inclusion criteria included an FVC of $\geqslant 50 \%$ of predicted value (according to the Japanese predicted normal equations) [15] and single-breath diffusing capacity for carbon monoxide 
(DLCO) of $30-79 \%$ of predicted value. Exclusion criteria included: elevated liver enzymes ( $>1.5$ times the upper limit of the normal range); relevant airway obstruction; requirement for $\geqslant 15 \mathrm{~h} \cdot \mathrm{day}^{-1}$ supplemental oxygen; treatment with oral corticosteroids at unstable doses or in excess of the equivalent of prednisone $15 \mathrm{mg} \cdot \mathrm{day}^{-1}$, or with ketoconazole or atazanavir; an expectation of undergoing lung transplantation or of having rapidly deteriorating disease; or a life expectancy of $<3$ months from screening. Patients who had been receiving a steady dose of pirfenidone for $\geqslant 3$ months were eligible for inclusion and were enrolled according to a pre-specified stratification scheme (described in the following section).

The trial was carried out in compliance with the Declaration of Helsinki (October 1996), and in accordance with the International Conference on Harmonisation Good Clinical Practice (GCP) guidelines and Japanese GCP regulations (Ministry of Health and Welfare Ordinance Number 28; March 27, 1997). All patients provided written informed consent before entering the study. The patients' safety was monitored by an independent data monitoring committee (IDMC). The trial was registered at www.clinicaltrials.gov with identifier number NCT01136174.

\section{Study design}

This study was a randomised, double-blind (with respect to nintedanib), placebo-controlled (within dose group), multicentre, dose-escalation trial. It consisted of a screening visit occurring 5-21 days before the start of treatment, a 14-day (cohorts 1 and 2) or 28-day (cohort 3) treatment period, an end-of-treatment visit 7 days after the last dose (or on premature treatment discontinuation) and a follow-up visit 3 weeks after the end-of-treatment visit (fig. 1). The treatment period included four (cohorts 1 and 2) or six (cohort 3) visits for pharmacokinetic sampling and safety assessments after the initiation of nintedanib treatment.

Patients were randomised to three cohorts using a stepwise approach, with IDMC safety review before transition to a higher dose group. Patients in cohort 1 were randomised to receive nintedanib $50 \mathrm{mg}$ twice daily or placebo for 14 days; patients in cohort 2 were randomised to receive nintedanib $100 \mathrm{mg}$ twice daily or placebo for 14 days; and patients in cohort 3 were randomised to nintedanib $150 \mathrm{mg}$ twice daily
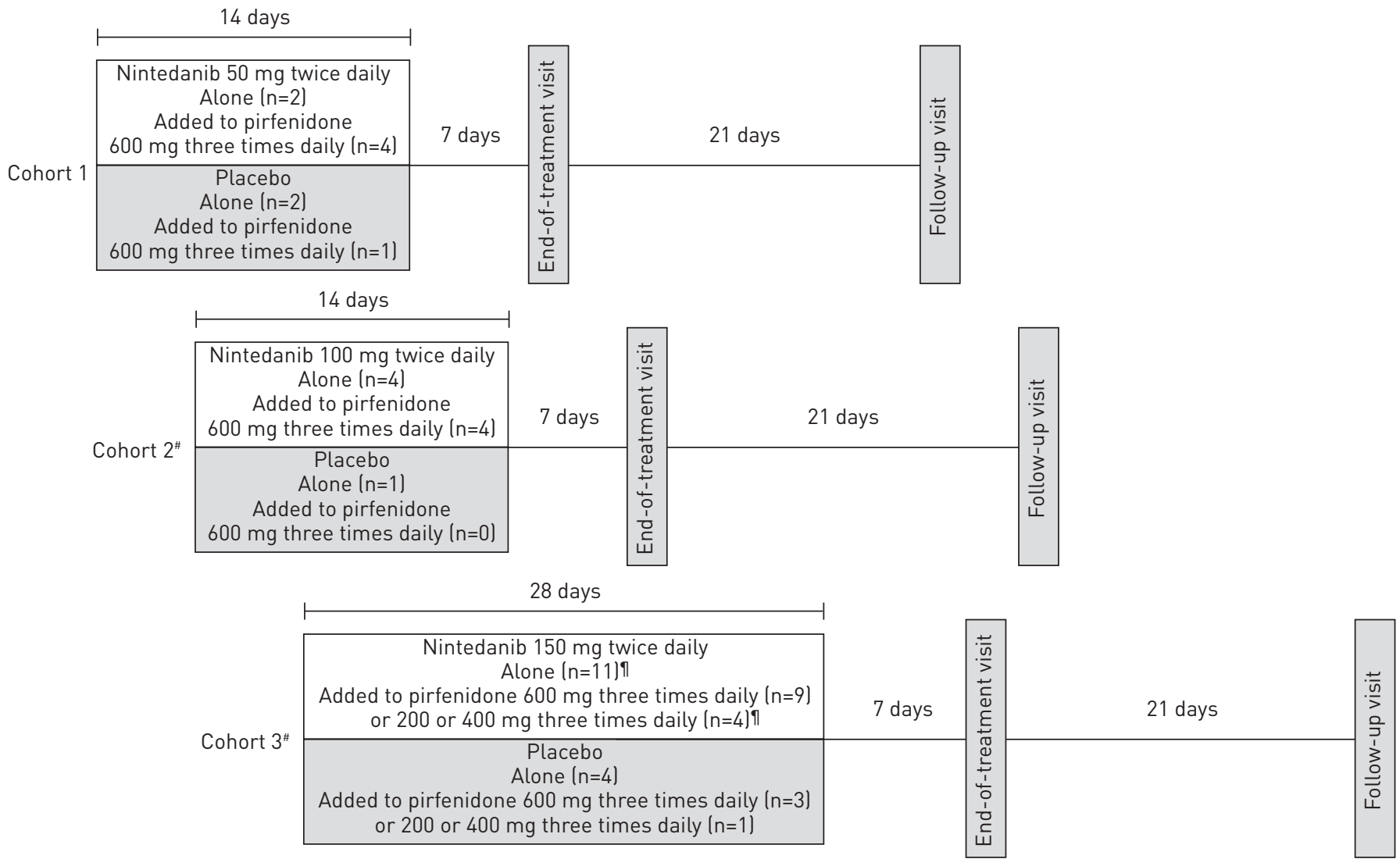

FIGURE 1 Study design and distribution of patients. " : patients' safety was reviewed by an independent data monitoring committee before patients were transitioned to these cohorts; ${ }^{9}$ : two patients withdrew before study completion. 
or placebo for 28 days (fig. 1). Patients who had been receiving a steady dose of pirfenidone $600 \mathrm{mg}$ three times daily for $\geqslant 3$ months prior to inclusion were stratified to each cohort, and were included in the safety and pharmacokinetic analyses. Patients on a steady dose of pirfenidone 200 or $400 \mathrm{mg}$ three times daily for $\geqslant 3$ months prior to inclusion were allowed to participate in cohort 3 only and were included in safety analyses, but not in the pharmacokinetic analysis. It was planned that approximately half of every nintedanib and placebo group would be taking pirfenidone, except the placebo group in cohort 3 , in which it was planned that two-thirds of the patients would be receiving pirfenidone. Pirfenidone was given as prescribed, after breakfast, lunch and dinner.

\section{Safety analyses}

All treated patients were included in the safety analyses. The safety end-points assessed were the incidence and intensity (mild, moderate or severe) of adverse events, withdrawal due to adverse events, routine laboratory tests, lung function measurements (FVC, forced expiratory volume in $1 \mathrm{~s} \mathrm{(FEV1)} \mathrm{and} \mathrm{DLCO),}$ blood pressure and pulse rate. Analyses of adverse events focused on treatment-emergent events, defined as those occurring up to 28 days after the completion of study medication, or starting before the first drug intake and deteriorating during treatment. Laboratory tests, lung function and vital signs were measured at screening, baseline, on days 2, 7 and 14 (plus days 21 and 28 for cohort 3) of treatment, and at the end-of-treatment visit. Safety results for patients receiving placebo with or without pirfenidone were grouped across all cohorts.

\section{Pharmacokinetic analyses}

For quantification of plasma concentrations of nintedanib, its metabolites (BIBF 1202 ZW and BIBF 1202 glucuronide) and pirfenidone, $\sim 4 \mathrm{~mL}$ of venous blood was collected during study visits (pre-dose and at time-points from $30 \mathrm{~min}$ to $72 \mathrm{~h}$ after drug administration at steady state). Samples for pharmacokinetic assessment of pirfenidone were taken before and after the breakfast and lunch doses (pre-dose and at time-points from $30 \mathrm{~min}$ to $12 \mathrm{~h}$ after drug administration). Plasma concentrations of nintedanib, its metabolites and pirfenidone were determined using a validated liquid chromatography-tandem mass spectrometry assay (Nuvisan Pharma Services GmbH \& Co. KG, Neu-Ulm, Germany).

The pharmacokinetic parameters calculated for nintedanib and pirfenidone included: the area under the concentration-time curve of the analyte in plasma at a steady state over a uniform dosing interval $\tau$ $(\mathrm{AUC} \tau, \mathrm{ss})$ and over the time interval from $\mathrm{t} 1$ to $\mathrm{t} 2$ (AUCt1-t2,ss); maximum concentration of the analyte in plasma at steady state over a uniform dosing interval $\tau$ (Cmax,ss); time from dosing to maximum concentration of the analyte in plasma at steady state over a uniform dosing interval $\tau$ (tmax,ss); terminal half-life of the analyte in plasma at steady state $(\mathrm{t} 1 / 2, \mathrm{ss})$; apparent clearance of the analyte in plasma after extravascular administration at steady state (CL/F,ss) (nintedanib only); apparent volume of distribution during the terminal phase $\lambda z$ following extravascular administration at steady state $(\mathrm{Vz} / \mathrm{F}, \mathrm{s})$ (nintedanib only); accumulation ratios based on AUCt1-t2,ss and Cmax,ss (nintedanib only); and ratios of Cmax,ss and AUCt1-t2,ss of the test treatment to the Cmax,ss and AUCt1-t2,ss of the reference treatment (pirfenidone only). Pharmacokinetics were assessed for nintedanib and its metabolites when it was given alone and when it was added to ongoing pirfenidone therapy (parallel-group comparison), and for pirfenidone with and without nintedanib co-administration (intra-individual comparison).

\section{Results}

\section{Patients}

A total of 66 patients were screened over eight sites, of whom 50 were randomised: six patients were randomised to receive nintedanib $50 \mathrm{mg}$ twice daily, eight to nintedanib $100 \mathrm{mg}$ twice daily, 24 to nintedanib $150 \mathrm{mg}$ twice daily and 12 to placebo (fig. 1). At screening, 26 patients were being treated with pirfenidone, five of whom entered cohort 1 (four randomised to nintedanib $50 \mathrm{mg}$ twice daily and one to placebo), four entered cohort 2 (all randomised to nintedanib $100 \mathrm{mg}$ twice daily) and 17 entered cohort 3 (13 randomised to nintedanib $150 \mathrm{mg}$ twice daily and four to placebo) (fig. 1). Of those randomised, 46 (92.0\%) patients completed the study; four patients from the $150 \mathrm{mg}$ twice daily group discontinued prematurely. There were no notable differences in baseline characteristics between groups (table 1). The mean age was 65.2 years and $70.0 \%$ of subjects were male. 10 patients were receiving systemic corticosteroids at baseline and four were receiving acetylcysteine.

\section{Safety outcomes}

Safety was assessed in all 50 randomised patients. A total of 23 (46.0\%) patients experienced at least one adverse event: four (50.0\%) patients receiving nintedanib $100 \mathrm{mg}$ twice daily, 15 (62.5\%) patients receiving nintedanib $150 \mathrm{mg}$ twice daily and four (33.3\%) patients receiving placebo (table 2). The adverse events were mild $(87 \%)$ or moderate $(13 \%)$ in intensity. The most common adverse events reported with nintedanib 
TABLE 1 Baseline patient demographics and characteristics

\begin{tabular}{|c|c|c|c|c|c|}
\hline & Placebo & $\begin{array}{c}\text { Nintedanib } \\
50 \mathrm{mg} \text { twice daily }\end{array}$ & $\begin{array}{c}\text { Nintedanib } \\
100 \mathrm{mg} \text { twice daily }\end{array}$ & $\begin{array}{c}\text { Nintedanib } \\
150 \mathrm{mg} \text { twice daily }\end{array}$ & Total \\
\hline Subjects $n$ & 12 & 6 & 8 & 24 & \\
\hline Age years & $64.1 \pm 10.3$ & $66.7 \pm 2.9$ & $67.5 \pm 7.4$ & $64.7 \pm 8.5$ & $65.2 \pm 8.2$ \\
\hline Height cm & $166.2 \pm 7.0$ & $159.3 \pm 7.2$ & $158.3 \pm 7.5$ & $159.5 \pm 7.8$ & $160.9 \pm 7.9$ \\
\hline Weight kg & $69.1 \pm 12.1$ & $58.6 \pm 7.5$ & $63.9 \pm 9.7$ & $62.1 \pm 13.2$ & $63.6 \pm 12.1$ \\
\hline Never-smokers & $3(25.0)$ & $1(16.7)$ & $3(37.5)$ & $7(29.2)$ & $14(28.0)$ \\
\hline FVC L & $2.63 \pm 0.7$ & $2.14 \pm 0.6$ & $2.13 \pm 0.5$ & $2.39 \pm 0.7$ & $2.38 \pm 0.7$ \\
\hline FVC $\%$ predicted & $72.9 \pm 14.7$ & $68.4 \pm 9.4$ & $73.4 \pm 10.4$ & $76.3 \pm 15.6$ & $74.1 \pm 13.9$ \\
\hline FEV 1 L & $2.22 \pm 0.6$ & $1.85 \pm 0.5$ & $1.72 \pm 0.4$ & $1.98 \pm 0.5$ & $1.98 \pm 0.5$ \\
\hline$D$ Lco $\mathrm{mL} \cdot \mathrm{min}^{-1} \cdot \mathrm{mmHg}^{-1}$ & $11.37 \pm 3.7$ & $11.10 \pm 2.7$ & $10.08 \pm 3.3$ & $9.31 \pm 4.0$ & $10.14 \pm 3.7$ \\
\hline DLco \% predicted & $59.2 \pm 13.6$ & $67.8 \pm 10.5$ & $58.5 \pm 16.9$ & $53.0 \pm 13.8$ & $57.2 \pm 14.4$ \\
\hline
\end{tabular}

Data are presented as $\mathrm{n}(\%)$ or mean \pm SD, unless otherwise stated. FVC: forced vital capacity; FEV1: forced expiratory volume in $1 \mathrm{~s}$; DLCo: diffusing capacity of the lung for carbon monoxide; $\mathrm{PaO}_{2}$ : arterial oxygen tension.

$150 \mathrm{mg}$ twice daily were vomiting (five patients, all receiving nintedanib in addition to ongoing pirfenidone therapy) and nausea (five patients, four receiving nintedanib in addition to ongoing pirfenidone therapy). One serious adverse event (malignant hepatic neoplasm) was reported in the nintedanib $150 \mathrm{mg}$ twice daily group during the follow-up period; this was not considered to be related to the study drug (previous computed tomography scans showed that the tumour was possibly present before study enrolment). Drug-related adverse events were reported by the investigator for $13(26.0 \%)$ patients, most of which occurred in patients receiving nintedanib $150 \mathrm{mg}$ twice daily (10 patients, seven receiving nintedanib in addition to ongoing pirfenidone therapy). The adverse events that led to discontinuation of study medication were increases in transaminase levels in three patients (all with nintedanib $150 \mathrm{mg}$ twice daily, one with co-administration of pirfenidone $200 \mathrm{mg}$ three times daily) and vomiting in one patient receiving nintedanib $150 \mathrm{mg}$ twice daily and pirfenidone $200 \mathrm{mg}$ three times daily. These adverse events resolved after treatment discontinuation. Photosensitivity was reported in one patient receiving pirfenidone alone and rash in one patient receiving pirfenidone with nintedanib $150 \mathrm{mg}$ twice daily. FVC, FEV1 and DLCO remained stable in all groups. There were no consistent changes in blood pressure or pulse rate and observed changes were not considered related to the study medication by the investigator.

\section{Pharmacokinetic outcomes}

After multiple dosing, maximum plasma concentrations of nintedanib were reached $2-4 \mathrm{~h}$ after dosing and a steady state was reached by day 7. Mean plasma concentrations of nintedanib after multiple dosing (day 14 for cohorts 1 and 2, day 28 for cohort 3) are shown in figure 2. For the $150 \mathrm{mg}$ twice daily dose, mean plasma concentrations of nintedanib were lower when nintedanib was added to ongoing pirfenidone therapy, but high variability was observed.

After 28 days' treatment with nintedanib $150 \mathrm{mg}$ twice daily, geometric means (gMean) of Cmax,ss and AUC $\tau$,ss of nintedanib were $41 \%$ lower (23.5 versus $39.7 \mathrm{ng} \cdot \mathrm{mL}^{-1}$ ) and $32 \%$ lower (149 versus $\left.218 \mathrm{~h} \cdot \mathrm{ng} \cdot \mathrm{mL}^{-1}\right)$, respectively, when nintedanib was added to ongoing pirfenidone therapy, but the distribution of individual values overlapped (fig. 3). Values for gMean t1/2,ss and median tmax,ss were similar when nintedanib was given alone as when given in addition to ongoing pirfenidone therapy (27.5 versus $28.4 \mathrm{~h}$ and 3.9 versus $3.9 \mathrm{~h}$, respectively) (table 3). Mean CL/F,ss was $11500 \mathrm{~mL} \cdot \mathrm{min}^{-1}$ in the absence of pirfenidone and $16800 \mathrm{~mL} \cdot \mathrm{min}^{-1}$ when nintedanib was added to pirfenidone, and mean $\mathrm{Vz} / \mathrm{F}$,ss was 27 $300 \mathrm{~L}$ in the absence of pirfenidone and $41200 \mathrm{~L}$ when added to ongoing pirfenidone (table 3). Mean RA, $\mathrm{AUC}_{0-12}$ was 1.5 in the absence of pirfenidone and 1.7 when added to ongoing pirfenidone and mean RA, $\mathrm{C}_{\max }$ was 1.1 in the absence of pirfenidone and 1.3 when added to ongoing pirfenidone (table 3 ). Pirfenidone therapy had no effect on nintedanib accumulation ratios ( $R A, C_{\max }$ and $\mathrm{RA}_{\mathrm{AU}} \mathrm{AUC}_{0-12}$ ) after multiple doses of nintedanib $150 \mathrm{mg}$ twice daily (table 3 ). The effect of adding nintedanib to ongoing pirfenidone therapy on the pharmacokinetic parameters of nintedanib was similar for the nintedanib $100 \mathrm{mg}$ twice daily dose as for the $150 \mathrm{mg}$ twice daily dose (table 3). Measurements of pharmacokinetic parameters were not obtained from enough patients receiving nintedanib $50 \mathrm{mg}$ twice daily to adequately evaluate whether ongoing pirfenidone therapy had any effect. 


\begin{tabular}{|c|c|c|c|c|c|c|c|c|}
\hline & \multicolumn{2}{|r|}{ Placebo $^{\#}$} & \multicolumn{2}{|c|}{ Nintedanib 50 mg twice daily" } & \multicolumn{2}{|c|}{ Nintedanib 100 mg twice daily ${ }^{+}$} & \multicolumn{2}{|c|}{ Nintedanib $150 \mathrm{mg}$ twice daily } \\
\hline & Alone & $\begin{array}{l}\text { Added to ongoing } \\
\text { pirfenidone }\end{array}$ & Alone & $\begin{array}{l}\text { Added to ongoing } \\
\text { pirfenidone }\end{array}$ & Alone & $\begin{array}{l}\text { Added to ongoing } \\
\text { pirfenidone }\end{array}$ & Alone & $\begin{array}{l}\text { Added to ongoing } \\
\text { pirfenidone }\end{array}$ \\
\hline Subjects n & 7 & 5 & 2 & 4 & 4 & 4 & 11 & 13 \\
\hline Any AE & $2(28.6)$ & $2(40.0)$ & 0 & 0 & $3(75.0)$ & $1(25.0)$ & $6(54.5)$ & $9(69.2)$ \\
\hline Serious AEs & 0 & 0 & 0 & 0 & 0 & 0 & $1(9.1)$ & 0 \\
\hline $\begin{array}{l}\text { Investigator-defined } \\
\text { drug-related AEs }\end{array}$ & $1(14.3)$ & $1(20.0)$ & 0 & 0 & $1(25.0)$ & 0 & $3(27.3)$ & $7(53.8)$ \\
\hline \multicolumn{9}{|l|}{ Most common AEs $f$} \\
\hline Vomiting & 0 & 0 & 0 & 0 & 0 & 0 & 0 & $5(38.5)$ \\
\hline Nausea & 0 & 0 & 0 & 0 & 0 & 0 & $1(9.1)$ & $4(30.8)$ \\
\hline Diarrhoea & 0 & 0 & 0 & 0 & 0 & 0 & $2(18.2)$ & $2(15.4)$ \\
\hline Nasopharyngitis & 0 & 0 & 0 & 0 & $1(25.0)$ & 0 & 0 & $2(15.4)$ \\
\hline Abdominal discomfort & 0 & $1(20.0)$ & 0 & 0 & 0 & 0 & $1(9.1)$ & 0 \\
\hline Stomatitis & 0 & 0 & 0 & 0 & $1(25.0)$ & 0 & 0 & $1(7.7)$ \\
\hline $\begin{array}{l}\text { Alanine aminotransferase } \\
\text { increased }^{\# \#}\end{array}$ & 0 & 0 & 0 & 0 & 0 & 0 & $2(18.2)$ & 0 \\
\hline $\begin{array}{l}\text { Aspartate aminotransferase } \\
\text { increased }^{\# \#}\end{array}$ & 0 & 0 & 0 & 0 & 0 & 0 & $2(18.2)$ & 0 \\
\hline $\begin{array}{l}\text { AEs leading to } \\
\text { discontinuation of } \\
\text { study drug }\end{array}$ & 0 & 0 & 0 & 0 & 0 & 0 & $2(18.2)$ & $2(15.4)$ \\
\hline Transaminases increased & 0 & 0 & 0 & 0 & 0 & 0 & $2(18.2)$ & $1(7.7)$ \\
\hline Vomiting & 0 & 0 & 0 & 0 & 0 & 0 & 0 & $1(7.7)$ \\
\hline
\end{tabular}



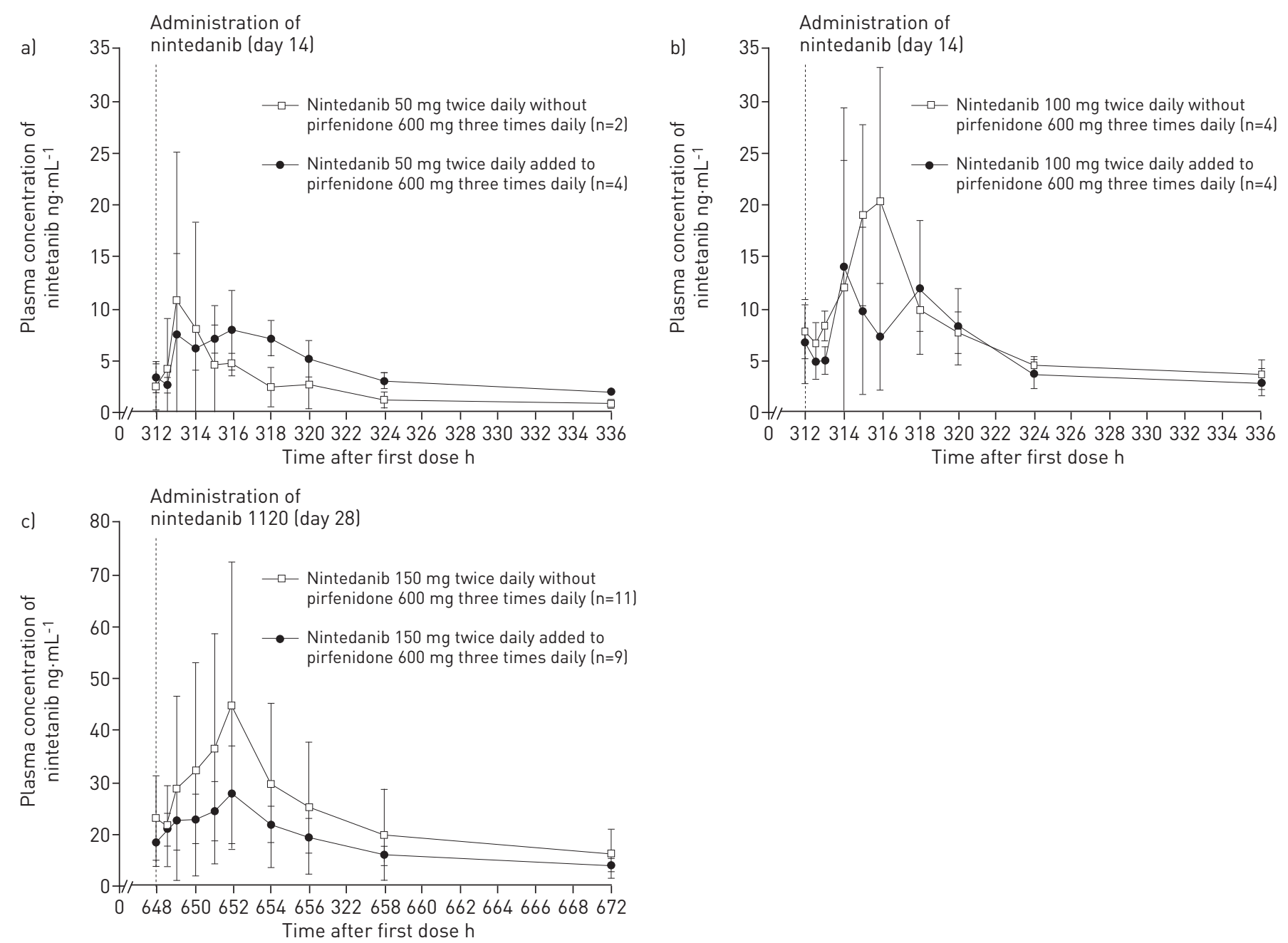

FIGURE 2 Arithmetic mean \pm SD plasma concentration-time profiles of nintedanib after a) multiple dosing of nintedanib 50 mg twice daily (day 14 ), b) 100 mg twice daily (day 14) and c) $150 \mathrm{mg}$ twice daily (day 28) given alone and added to ongoing pirfenidone therapy (600 mg three times daily).

After multiple doses of nintedanib alone, maximum plasma concentrations of the nintedanib metabolites BIBF $1202 \mathrm{ZW}$ and BIBF 1202 glucuronide were reached 3-4 and 0.8-4.0 h, respectively, after drug administration, with gMean t1/2,ss values of approximately 23 and $46-56 \mathrm{~h}$, respectively. When nintedanib was added to ongoing pirfenidone therapy, values for tmax,ss were 3-5 and 0.7-8.0 h for BIBF $1202 \mathrm{ZW}$ and BIBF 1202 glucuronide, respectively, while t1/2,ss was $27-26 \mathrm{~h}$ for BIBF $1202 \mathrm{ZW}$ and $38-43 \mathrm{~h}$ for BIBF 1202 glucuronide. For the nintedanib $150 \mathrm{mg}$ twice daily dose, gMean Cmax,ss was 51\% lower (15.4 versus $33.2 \mathrm{ng} \cdot \mathrm{mL}^{-1}$ ) for BIBF $1202 \mathrm{ZW}$ and 16\% lower (107 versus $128 \mathrm{ng} \cdot \mathrm{mL}^{-1}$ ) for BIBF 1202 glucuronide when nintedanib was given in addition to ongoing pirfenidone therapy. AUC $\tau$,ss was $50 \%$ lower (118 versus $\left.237 \mathrm{~h} \cdot \mathrm{ng} \cdot \mathrm{mL}^{-1}\right)$ for BIBF $1202 \mathrm{ZW}$ and $20 \%$ lower $\left(1100\right.$ versus $\left.1380 \mathrm{~h} \cdot \mathrm{ng} \cdot \mathrm{mL}^{-1}\right)$ for BIBF 1202 glucuronide when nintedanib was given in addition to ongoing pirfenidone therapy. The effect of pirfenidone therapy on the pharmacokinetic parameters of BIBF $1202 \mathrm{ZW}$ and BIBF 1202 glucuronide in the nintedanib $100 \mathrm{mg}$ twice daily group was similar to that seen in the $150 \mathrm{mg}$ twice daily group.

Maximum plasma concentrations of pirfenidone administered alone at the steady state were reached 1-1.6 $\mathrm{h}$ after the breakfast dose and $1-2 \mathrm{~h}$ after the lunch dose, with a gMean $\mathrm{t} 1 / 2, \mathrm{ss}$ of approximately 3-4 h (table 4). Plasma concentrations and pharmacokinetic parameters of pirfenidone were not affected by co-administration with nintedanib (table 4 ).

\section{Discussion}

The results of this study show that nintedanib $150 \mathrm{mg}$ twice daily had an acceptable safety and tolerability profile in Japanese patients with IPF when given alone or when added to ongoing pirfenidone therapy, but with more reports of nausea and vomiting when nintedanib was added to ongoing pirfenidone than when given alone. All the adverse events reported in this trial were mild or moderate in intensity. The most 

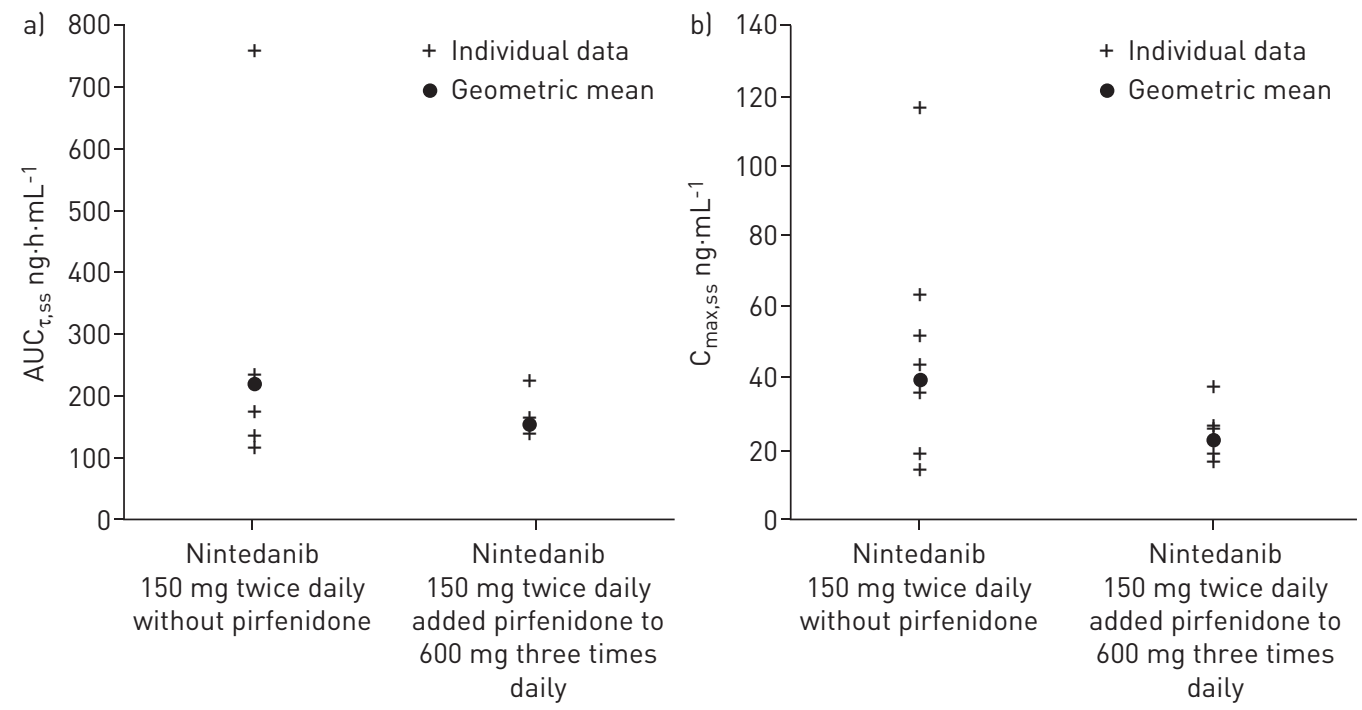

FIGURE 3 Individual and geometric mean area under the concentration-time curve of the analyte in plasma at a steady state over a uniform dosing interval $\tau$ (AUC $\tau$, ss) and maximum concentration of the analyte in plasma at steady state over a uniform dosing interval $\tau(\mathrm{Cmax}, \mathrm{ss})$ values for nintedanib $150 \mathrm{mg}$ twice daily given alone and added to ongoing pirfenidone therapy (600 $\mathrm{mg}$ three times daily).

common adverse events reported in patients receiving nintedanib were gastrointestinal side-effects, which were reported by approximately one-third of patients taking nintedanib alone or nintedanib in addition to already prescribed pirfenidone therapy. Nausea, vomiting and diarrhoea were reported only by patients in the nintedanib $150 \mathrm{mg}$ twice daily group: five (20.8\%) patients on this dose reported nausea, five (20.8\%) patients reported vomiting and four (16.7\%) patients reported diarrhoea. Gastrointestinal adverse events were not unexpected, as gastrointestinal side-effects have been observed in previous trials of nintedanib (at doses up to $150 \mathrm{mg}$ twice daily) and pirfenidone (at doses up to $3600 \mathrm{mg} \cdot \mathrm{day}^{-1}$ ) in patients with IPF [6-9, 16], and in phase I and II studies of nintedanib at doses of $50 \mathrm{mg}$ once daily to $300 \mathrm{mg}$ twice daily in patients with advanced solid tumours and advanced non-small cell lung cancer [17, 18]. In this study, of the patients receiving nintedanib $150 \mathrm{mg}$ twice daily in combination with pirfenidone, $69.2 \%$ reported adverse events, compared to $54.5 \%$ of patients receiving nintedanib $150 \mathrm{mg}$ twice daily alone. The difference was mostly due to nausea (reported by four (30.8\%) patients given nintedanib $150 \mathrm{mg}$ twice daily in addition to pirfenidone and one (9.1\%) patient given nintedanib $150 \mathrm{mg}$ twice daily alone) and vomiting (reported by five (38.5\%) of patients given nintedanib $150 \mathrm{mg}$ twice daily in addition to pirfenidone and none given nintedanib alone); diarrhoea was not more frequently reported when nintedanib $150 \mathrm{mg}$ twice daily was given in addition to pirfenidone than when it was given alone. Vomiting led to discontinuation of study medication in one patient (treated with nintedanib $150 \mathrm{mg}$ twice daily in addition to pirfenidone $200 \mathrm{mg}$ three times daily). Other adverse events associated with pirfenidone (but not nintedanib) include a dose-related increase in skin photosensitivity and rash $[8,11,12]$. The incidence of these adverse events did not increase when pirfenidone was co-administered with nintedanib in this study.

Increases in transaminase levels led to discontinuation of study medication in three patients (all treated with nintedanib $150 \mathrm{mg}$ twice daily). The elevations in transaminases were reversible and resolved after treatment discontinuation. In a phase I study in Japanese patients with advanced solid tumours, liver enzyme elevations led to treatment discontinuation in three (25\%) patients treated with nintedanib $200 \mathrm{mg}$ twice daily [19]. In the phase II TOMORROW trial in patients with IPF, clinically significant elevations in liver enzyme levels were observed in six (7.1\%) patients receiving nintedanib $150 \mathrm{mg}$ twice daily [6]; these elevations were reversible. In the phase III INPULSIS trials, investigators were given recommendations for management of liver enzyme elevations through treatment interruption, dose reduction or treatment discontinuation. Across the two trials, elevations in liver transaminases (three or more times the upper limit of normal for aspartate aminotransferase or alanine aminotransferase) were observed in $5.0 \%$ of patients in the nintedanib groups and $0.7 \%$ of patients in the placebo groups. In general, elevations in liver enzymes returned to normal following treatment interruption, dose reduction or treatment discontinuation. There were no cases of Hy's law in patients treated with nintedanib [7].

A limitation of this study in evaluating the safety and tolerability of nintedanib was its relatively short duration. An extension trial investigating the long-term safety and tolerability of nintedanib given in addition to pirfenidone is ongoing (www.clinicaltrials.gov identifier number NCT01417156). 
TABLE 3 Pharmacokinetic parameters of nintedanib after multiple doses (steady state)

\section{Nintedanib $\mathbf{5 0} \mathbf{~ m g}$ twice dail}

\begin{tabular}{ccc}
\hline $\begin{array}{c}\text { Patients without/ } \\
\text { with ongoing } \\
\text { pirfenidone } \\
\text { therapy }\end{array}$ & Alone & $\begin{array}{c}\text { Added to ongoin } \\
\text { pirfenidone 600 m } \\
\text { three times daily }\end{array}$ \\
$2 / 4$ & $33.7(165)$ & $67.9(16.7)$ \\
$2 / 4$ & $9.1(173)$ & $10.9(50.3)$ \\
$2 / 4$ & $2.4(1.0-3.9)$ & $3.9(1.0-6.0)$ \\
$0 / 4$ & $\mathrm{NA}$ & $25.4(25.5)$ \\
$2 / 4$ & 24700 & $12300(16.7)$ \\
& $(165.0)$ & $27000(39.5)$ \\
$0 / 4$ & $\mathrm{NA}$ & $2.2(13.8)$ \\
$0 / 3$ & $\mathrm{NA}$ & $1.9(62.1)$ \\
$2 / 4$ & $2.3(26.6)$ &
\end{tabular}

$2.3(26.6)$

$1.9(62.1)$

$2 / 4$

\section{Nintedanib $100 \mathrm{mg}$ twice daily}

\begin{tabular}{|c|c|c|}
\hline $\begin{array}{l}\text { Patients without/ } \\
\text { with ongoing } \\
\text { pirfenidone }\end{array}$ & Alone & $\begin{array}{l}\text { Added to ongoing } \\
\text { pirfenidone } 600 \mathrm{mg} \\
\text { three times daily }\end{array}$ \\
\hline
\end{tabular}

\section{Nintedanib $150 \mathrm{mg}$ twice daily}

\begin{tabular}{|c|c|c|}
\hline $\begin{array}{l}\text { Patients without/ } \\
\text { with ongoing } \\
\text { pirfenidone } \\
\text { therapy }\end{array}$ & Alone & $\begin{array}{l}\text { Added to ongoing } \\
\text { pirfenidone } 600 \mathrm{mg} \\
\text { three times daily }\end{array}$ \\
\hline
\end{tabular}

therapy

$4 / 3$

AUC $_{\tau, \mathbf{s s}}$

$\mathrm{h} \cdot \mathrm{ng} \cdot \mathrm{mL}^{-1}$

$C_{\text {max,ss }}$

$\mathrm{ng} \cdot \mathrm{mL}^{-1}$

tmax,ss $h$

t1/2,ss $h$

$\mathrm{CL} / \mathrm{F}, \mathrm{ss}$

$\mathrm{mL} \cdot \mathrm{min}^{-1}$

$\mathrm{V}_{\mathrm{z} / \mathrm{F}, \mathbf{s s} \mathrm{L}}$

$115.0(32.4)$

86.0 (62.7)

$9 / 7$

$20.0(64.5)$

13.8 (113.0)

$3.4(2.0-4.1) \quad 2.0(2.0-6.0)$

$23.4(22.4)$

$30.5(20.1)$

14500

19400 (62.7)

(32.4)

29300

(54.7)

RA,AUC $0-12$

Data are presented as $\mathrm{n}$, geometric mean (geometric coefficient of variation \%) or median (range). AUC $\tau$,ss: area under the concentration-time curve of the analyte in plasma at a steady state over a uniform dosing interval $\tau_{\text {; }}$ Cmax,ss: maximum concentration of the analyte in plasma at steady state over a uniform dosing interval $\tau$; tmax,ss: time from dosing to maximum analyte in plasma after extravascular administration at steady state; $V_{z} / F, s s$ : apparent volume of distribution during the terminal phase $\lambda z$ following extravascular administration at steady state; $\mathrm{RA}_{\mathrm{A}} \mathrm{AUC}_{0-12}$ : accumulation ratio based on $\mathrm{AUC} \mathrm{C}_{0} 12, \mathrm{ss}$; $\mathrm{RA}, \mathrm{Cmax}$ : accumulation ratio based on $\mathrm{C}_{\text {max,ss; }} \mathrm{NA}$ : not applicable. 
TABLE 4 Pharmacokinetic parameters (steady state) of pirfenidone $600 \mathrm{mg}$ three times daily

\begin{tabular}{|c|c|c|c|c|c|c|c|c|c|}
\hline & \multicolumn{3}{|c|}{ Cohort 1} & \multicolumn{3}{|c|}{ Cohort 2} & \multicolumn{3}{|c|}{ Cohort 3} \\
\hline & $\begin{array}{l}\text { Patients without/ } \\
\text { with ongoing } \\
\text { pirfenidone } \\
\text { therapy }\end{array}$ & Alone & $\begin{array}{c}\text { With } \\
\text { nintedanib } \\
50 \text { mg twice } \\
\text { daily }\end{array}$ & $\begin{array}{l}\text { Patients without/ } \\
\text { with ongoing } \\
\text { pirfenidone } \\
\text { therapy }\end{array}$ & Alone & $\begin{array}{c}\text { With } \\
\text { nintedanib } \\
100 \text { mg twice } \\
\text { daily }\end{array}$ & $\begin{array}{l}\text { Patients without/ } \\
\text { with ongoing } \\
\text { pirfenidone } \\
\text { therapy }\end{array}$ & Alone & $\begin{array}{c}\text { With } \\
\text { nintedanib } \\
150 \text { mg twice } \\
\text { daily }\end{array}$ \\
\hline \multicolumn{10}{|l|}{ After breakfast } \\
\hline $\mathrm{AUC} 0-4, \mathrm{ss} \mathrm{h} \cdot \mathrm{ng} \cdot \mathrm{mL}^{-1}$ & $4 / 4$ & $34400(36.3)$ & 34300 (39.9) & $3 / 3$ & $45800(26.6)$ & $35000(32.2)$ & $9 / 7$ & $32500(21.2)$ & $35900(21.8)$ \\
\hline $\mathrm{C}_{\max , \mathrm{ss}} \mathrm{ng} \cdot \mathrm{mL}^{-1}$ & $4 / 4$ & 11900 (28.9) & $12800(44.3)$ & $4 / 3$ & 14600 (41.5) & $15300(51.1)$ & $9 / 8$ & $11200(26.6)$ & $12600(27.2)$ \\
\hline$t_{\max , s s} \mathrm{~h}$ & $4 / 4$ & $1.6(1.0-3.0)$ & $0.7(0.5-2.0)$ & $4 / 3$ & $1.5(0.5-3.0)$ & $2.0(0.5-2.0)$ & $9 / 8$ & $1.1(0.5-3.0)$ & $0.8(0.5-3.9)$ \\
\hline RAUC $_{0-4, s s}, T / R$ & $0 / 4$ & \multicolumn{2}{|c|}{$1.0(32.2)$} & $0 / 2$ & \multicolumn{2}{|c|}{$0.7(51.8)$} & $0 / 7$ & \multicolumn{2}{|c|}{$1.1(13.1)$} \\
\hline $\mathrm{RC}_{\max , \mathrm{ss}, \mathrm{T} / \mathrm{R}}$ & $0 / 4$ & \multicolumn{2}{|c|}{$1.1(45.1)$} & $0 / 3$ & \multicolumn{2}{|c|}{$1.0(38.6)$} & $0 / 8$ & \multicolumn{2}{|c|}{$1.1(12.4)$} \\
\hline \multicolumn{10}{|l|}{ After lunch } \\
\hline$A \cup C_{0-8, s s} h \cdot n g \cdot \mathrm{mL}^{-1}$ & $4 / 4$ & $72800(40.7)$ & 71000 (40.8) & $3 / 3$ & $84100(11.4)$ & $71500(19.1)$ & $8 / 6$ & $60900(22.9)$ & $63600(27.7)$ \\
\hline $\mathrm{C}_{\max , \mathrm{ss}} \mathrm{ng} \cdot \mathrm{mL}^{-1}$ & $4 / 4$ & $14600(20.9)$ & 12000 (37.3) & $4 / 3$ & $15100(19.5)$ & $12100(10.7)$ & $9 / 8$ & $12900(30.2)$ & $12500(23.0)$ \\
\hline$t_{\max , s s} \mathrm{~h}$ & $4 / 4$ & $1.0(0.5-3.1)$ & $2.5(1.0-3.9)$ & $4 / 3$ & $2.0(1.0-3.0)$ & $4.0(2.0-4.0)$ & $9 / 8$ & $1.0(0.4-6.0)$ & $2.0(0.5-4.4)$ \\
\hline $\mathrm{t} 1 / 2, \mathrm{ss} \mathrm{h}$ & $4 / 3$ & $3.4(50.5)$ & $4.0(31.7)$ & $4 / 1$ & $3.5(49.0)$ & $3.6(\mathrm{NC})$ & $8 / 5$ & $3.1(40.6)$ & $3.2(39.1)$ \\
\hline RAUC $_{0-8, s s}, T / R$ & $0 / 4$ & \multicolumn{2}{|c|}{$1.0(4.7)$} & $0 / 2$ & \multicolumn{2}{|c|}{$0.9(21.2)$} & $0 / 5$ & \multicolumn{2}{|c|}{$1.0(14.6)$} \\
\hline $\mathrm{RC}_{\max , \mathrm{ss}}, \mathrm{T} / \mathrm{R}$ & $0 / 4$ & \multicolumn{2}{|c|}{$0.8(19.7)$} & $0 / 3$ & \multicolumn{2}{|c|}{$0.8(20.2)$} & $0 / 8$ & \multicolumn{2}{|c|}{$0.9(25.6)$} \\
\hline $\mathrm{AUC} 0-12, \mathrm{ss}^{\#} \mathrm{~h} \cdot \mathrm{ng} \cdot \mathrm{mL}^{-1}$ & $4 / 4$ & $108000(36.8)$ & $105000(40.3)$ & $3 / 3$ & $130000(16.0)$ & $107000(22.4)$ & $8 / 6$ & 92000 (18.3) & $102000(22.2)$ \\
\hline RAUC $_{0-12, s s}, T / R$ & $0 / 4$ & \multicolumn{2}{|c|}{$1.0(9.9)$} & $0 / 2$ & \multicolumn{2}{|c|}{$0.8(30.8)$} & $0 / 5$ & \multicolumn{2}{|c|}{$1.1(12.2)$} \\
\hline
\end{tabular}

Data are presented as $\mathrm{n}$, geometric mean (geometric coefficient of variation \%) or median (range). AUCt1-t2,ss: area under the concentration-time curve of the analyte in plasma at a steady state over the time interval from $\mathrm{t} 1$ to $\mathrm{t} 2$; Cmax,ss: maximum concentration of the analyte in plasma at steady state over a uniform dosing interval $\tau$; tmax,ss: time from dosing to

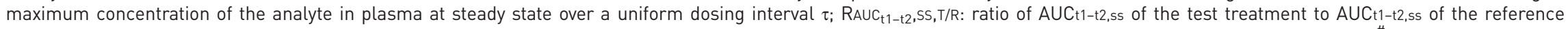

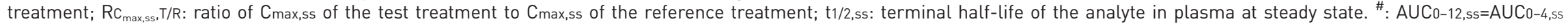
(post-dose after breakfast)+AUC0-8,ss (post-dose after lunch). NA: not applicable; NC: not calculated. 
The pharmacokinetic profile of nintedanib has previously been described in Japanese and Caucasian patients with advanced solid tumours $[18,19]$. Those studies suggest there is no difference in the pharmacokinetic behaviour of nintedanib between Japanese and Caucasian patients. Pharmacokinetic analyses of nintedanib revealed moderately fast absorption with a terminal half-life suitable for once- or twice-daily dosing. Maximum plasma concentrations and exposure increased with doses from $50 \mathrm{mg}$ once daily to $300 \mathrm{mg}$ twice daily, both after single administration and at a steady state [17]. Previous reports revealed all pharmacokinetic variables displayed a moderate-high variability, as expected for an oral compound [17, 19]. After multiple doses of nintedanib $150 \mathrm{mg}$ twice daily in patients with advanced solid tumours, values for tmax and half-life were similar to those observed in the $150 \mathrm{mg}$ twice daily group in this study. In this study, the exposure (maximal concentration and $\mathrm{AUC} \tau, \mathrm{ss}$ ) of nintedanib and its metabolites tended to be lower when nintedanib was added to ongoing pirfenidone therapy than when given alone; however, the distribution of individual values overlapped. Values for CL/F,ss and $\mathrm{V}_{\mathrm{z}} / \mathrm{F}$,ss of nintedanib tended to be higher when nintedanib was added to ongoing pirfenidone therapy, indicating that the bioavailability of nintedanib may be decreased by co-administration of pirfenidone. As the pathway of metabolism of the two drugs is different, the lower bioavailability of nintedanib when pirfenidone is co-administered with it may reflect reduced absorption. Nintedanib had no effect on the pharmacokinetics of pirfenidone.

In conclusion, further study is needed to evaluate the safety and tolerability profile of nintedanib when added to pirfenidone in patients with IPF. There was a trend toward lower exposure of nintedanib and its metabolites when nintedanib was added to ongoing pirfenidone therapy. Co-administration with nintedanib had no effect on the pharmacokinetics of pirfenidone. The efficacy of a pirfenidone/nintedanib regimen may be investigated in the future.

\section{Acknowledgements}

Medical writing assistance, supported financially by Boehringer Ingelheim, was provided by Elizabeth Ng and Wendy Morris, of Fleishman-Hillard Group, Ltd, during the preparation of this manuscript. The authors were fully responsible for all content and editorial decisions, were involved at all stages of manuscript development, and approved the final version.

\section{References}

1 American Thoracic Society. Idiopathic pulmonary fibrosis: diagnosis and treatment. International consensus statement. American Thoracic Society (ATS) and the European Respiratory Society (ERS). Am J Respir Crit Care Med 2000; 161: 646-664.

2 Raghu G, Collard HR, Egan JJ, et al. An official ATS/ERS/JRS/ALAT statement: idiopathic pulmonary fibrosis evidence-based guidelines for diagnosis and management. Am J Respir Crit Care Med 2011; 183: 788-824.

3 Fernandez IE, Eickelberg O. New cellular and molecular mechanisms of lung injury and fibrosis in idiopathic pulmonary fibrosis. Lancet 2012; 380: 680-688.

4 Wollin L, Maillet I, Quesniaux V, et al. Antifibrotic and anti-inflammatory activity of the tyrosine kinase inhibitor nintedanib in experimental models of lung fibrosis. J Pharmacol Exp Ther 2014; 349: 209-220.

5 Hilberg F, Roth GJ, Krssak M, et al. BIBF 1120: triple angiokinase inhibitor with sustained receptor blockade and good antitumor efficacy. Cancer Res 2008; 68: 4774-4782.

6 Richeldi L, Costabel U, Selman M, et al. Efficacy of a tyrosine kinase inhibitor in idiopathic pulmonary fibrosis. N Engl J Med 2011; 365: 1079-1087.

7 Richeldi L, du Bois RM, Raghu G, et al. Efficacy and safety of nintedanib in idiopathic pulmonary fibrosis. $N$ Engl J Med 2014; 370: 2071-2082.

8 Noble PW, Albera C, Bradford WZ, et al. Pirfenidone in patients with idiopathic pulmonary fibrosis (CAPACITY): two randomised trials. Lancet 2011; 377: 1760-1769.

9 King TEJr, Bradford WZ, Castro-Bernardini S, et al. A phase 3 trial of pirfenidone in patients with idiopathic pulmonary fibrosis. N Engl J Med 2014; 370: 2083-2092.

10 Taniguchi H, Ebina M, Kondoh Y, et al. Pirfenidone in idiopathic pulmonary fibrosis. Eur Respir J 2010; 35 : 821-829.

11 Valeyre D, Albera C, Bradford WZ, et al. Comprehensive assessment of the long-term safety of pirfenidone in patients with idiopathic pulmonary fibrosis. Respirology 2014; 19: 740-747.

12 European Medicines Agency. CHMP assessment report: Esbriet. www.ema.europa.eu/docs/en_GB/document library/EPAR_-_Public_assessment_report/human/002154/WC500103073.pdf Date last updated: December 16, 2010. Date last accessed: September 4, 2013.

13 Stopfer P, Rathgen K, Bischoff D, et al. Pharmacokinetics and metabolism of BIBF 1120 after oral dosing to healthy male volunteers. Xenobiotica 2011; 41: 297-311.

14 Japanese Respiratory Society. Idiopathic interstitial pneumonias: diagnosis and treatment. Nankodo 2004; 36-40.

15 Pulmonary Physiology Specialist Committee of the Japanese Respiratory Society. Predicted values of spirometry and arterial blood gas analysis in Japanese. J Jpn Respir Soc 2001; 39: 1-17.

16 Raghu G, Johnson WC, Lockhart D, et al. Treatment of idiopathic pulmonary fibrosis with a new antifibrotic agent, pirfenidone: results of a prospective, open-label Phase II study. Am J Respir Crit Care Med 1999; 159: 1061-1069.

17 Mross K, Stefanic M, Gmehling D, et al. Phase I study of the angiogenesis inhibitor BIBF 1120 in patients with advanced solid tumors. Clin Cancer Res 2010; 16: 311-319.

18 Reck M, Kaiser R, Eschbach C, et al. A phase II double-blind study to investigate efficacy and safety of two doses of the triple angiokinase inhibitor BIBF 1120 in patients with relapsed advanced non-small-cell lung cancer. Ann Oncol 2011; 22: 1374-1381.

19 Okamoto I, Kaneda H, Satoh T, et al. Phase I safety, pharmacokinetic, and biomarker study of BIBF 1120, an oral triple tyrosine kinase inhibitor in patients with advanced solid tumors. Mol Cancer Ther 2010; 9: 2825-2833. 